\title{
HIV Coinfection Is Associated with Low-Fitness rpoB Variants in Rifampicin-Resistant Mycobacterium tuberculosis
}

\author{
Chloé Loiseau, ${ }^{\mathrm{a}, \mathrm{b}}$ Daniela Brites, ${ }^{\mathrm{a}, \mathrm{b}}$ Miriam Reinhard, ${ }^{\mathrm{a}, \mathrm{b}}$ Kathrin Zürcher,c Sonia Borrell, ${ }^{\mathrm{a}, \mathrm{b}}$ Marie Ballif,c (D) Lukas Fenner, ${ }^{\mathrm{c}}$

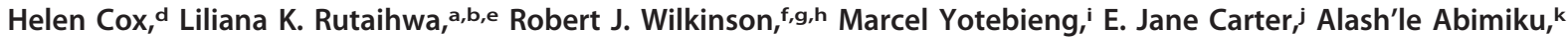 \\ Olivier Marcy, ${ }^{1, m}$ Eduardo Gotuzzo, ${ }^{n}$ Anchalee Avihingsanon, ${ }^{\circ}$ Nicola Zetola, ${ }^{\mathrm{p}}$ Basra Doulla, ${ }^{\mathrm{q}, \mathrm{r}}$ Erik C. Böttger, ${ }^{\mathrm{s}, \mathrm{t}}$ \\ Matthias Egger, ${ }^{c, u}$ Sebastien Gagneux ${ }^{a, b}$
}

\author{
aSwiss Tropical and Public Health Institute, Basel, Switzerland \\ buniversity of Basel, Basel, Switzerland \\ cInstitute of Social and Preventive Medicine, University of Bern, Bern, Switzerland \\ dnstitute of Infectious Disease and Molecular Medicine and Wellcome Centre for Infectious Disease Research in Africa, University of Cape Town, Cape Town, South Africa \\ elfakara Health Institute, Bagamoyo, Tanzania \\ fWellcome Centre for Infectious Diseases Research in Africa, University of Cape Town, Observatory, South Africa \\ gDepartment of Infectious Diseases, Imperial College London, London, United Kingdom \\ hFrancis Crick Institute, London, United Kingdom \\ 'Division of General Internal Medicine, Department of Medicine, Albert Einstein College of Medicine, Bronx, New York, USA \\ jDepartment of Medicine, Moi University School of Medicine, and Moi Teaching and Referral Hospital, Eldoret, Kenya \\ kInstitute of Human Virology, Abuja, Nigeria \\ 'Centre de Prise en Charge de Recherche et de Formation, Yopougon, Abidjan, Côte d'Ivoire \\ mBordeaux Population Health Research Center, Inserm U1219, University of Bordeaux, Bordeaux, France \\ nTB Research Unit, Instituto de Medicina Tropical Alexander von Humboldt, Universidad Peruana Cayetano Heredia, Lima, Peru \\ -The HIV Netherlands Australia Thailand (HIV-NAT) Research Collaboration, Thai Red Cross AIDS Research Centre and Tuberculosis Research Unit, Faculty of Medicine, \\ Chulalongkorn University, Bangkok, Thailand \\ PUniversity of Pennsylvania, Philadelphia, Pennsylvania, USA \\ aCentral Tuberculosis Reference Laboratory, Dar es Salaam, Tanzania \\ rNational Tuberculosis and Leprosy Programme, Dar es Salaam, Tanzania \\ sInstitute of Medical Microbiology, University of Zurich, Zurich, Switzerland \\ tSwiss National Center for Mycobacteria, Zurich, Switzerland \\ uCentre for Infectious Disease Epidemiology and Research, Faculty of Health Sciences, University of Cape \\ Town, Cape Town, South Africa
}

ABSTRACT We analyzed 312 drug-resistant genomes of Mycobacterium tuberculosis isolates collected from HIV-coinfected and HIV-negative TB patients from nine countries with a high tuberculosis burden. We found that rifampicin-resistant $M$. tuberculosis strains isolated from HIV-coinfected patients carried disproportionally more resistance-conferring mutations in $r p o B$ that are associated with a low fitness in the absence of the drug, suggesting these low-fitness $r p o B$ variants can thrive in the context of reduced host immunity.

KEYWORDS HIV-TB coinfection, Mycobacterium tuberculosis, drug resistance, fitness cost, rifampicin

\footnotetext{
uberculosis (TB), caused by members of the Mycobacterium tuberculosis complex, is a leading cause of death worldwide, killing more people than any other infectious disease. Among the many factors driving the global TB epidemics, two factors stand out as particularly important: antibiotic resistance and HIV coinfection (1). Although the impact of both of these factors individually is well recognized, the interaction between them is less clear and likely depends on the particular epidemiologic setting (2). HIV coinfection and drug-resistant TB often coexist in severe epidemics, which indicates
}

Citation Loiseau C, Brites D, Reinhard M, Zürcher K, Borrell S, Ballif M, Fenner L, Cox H, Rutaihwa LK, Wilkinson RJ, Yotebieng M, Carter EJ, Abimiku A, Marcy O, Gotuzzo E, Avihingsanon A, Zetola N, Doulla B, Böttger EC, Egger M, Gagneux S. 2020. HIV coinfection is associated with low-fitness rpoB variants in rifampicin-resistant Mycobacterium tuberculosis. Antimicrob Agents Chemother 64:e00782-20. https://doi.org/10.1128/AAC.00782-20. Copyright $\odot 2020$ Loiseau et al. This is an open-access article distributed under the terms of the Creative Commons Attribution 4.0 International license.

Address correspondence to Sebastien Gagneux, sebastien.gagneux@swisstph.ch. Received 23 April 2020 Returned for modification 18 June 2020 Accepted 23 July 2020 Accepted manuscript posted online 27 July 2020

Published 21 September 2020 
spread of drug-resistant $M$. tuberculosis strains from immunocompromised patients (3-5). The propensity of drug-resistant $M$. tuberculosis strains to spread is influenced by the fitness cost associated with drug resistance determinants (6). Specifically, bacterial strains that have acquired drug resistance-conferring mutations may be less transmissible than their susceptible counterparts, although this fitness cost can be ameliorated by compensatory mutations (7-10). Moreover, the effect of different resistanceconferring mutations on fitness can be heterogeneous (11). In the clinical setting, there is a selection for high-fitness and/or compensated drug-resistant $M$. tuberculosis strains in TB patients (12). However, in immunocompromised hosts, such as HIV-coinfected patients, even strains with low-fitness resistance mutations might propagate efficiently (13-15), which could partially explain why drug-resistant TB has been associated with HIV coinfection $(16,17)$. However, to date, no evidence directly supports the notion that the immunological environment created by HIV coinfection modifies the fitness of drug-resistant $M$. tuberculosis $(5,18,19)$.

In this study, we tested the hypothesis that resistance-conferring mutations with low fitness in $M$. tuberculosis are overrepresented among HIV-coinfected TB patients. We focused our analysis on isoniazid and rifampicin, the two most important first-line anti-TB drugs, for which resistance-conferring mutations have been shown to differ in their fitness effects when measured in the laboratory (11). In addition, the frequency of the resistance alleles found in a clinical setting correlates well with the in vitro fitness of strains $(12,20)$. To explore the association between HIV coinfection and the fitness effect of different drug resistance-conferring mutations in $M$. tuberculosis, we compiled a collection of drug-resistant strains using the global International Epidemiology Databases to Evaluate AIDS (leDEA, http://www.iedea.org) consortium $(21,22)$ as a platform. For this study, 312 strains were collected from HIV-coinfected and HIV uninfected TB patients originating from nine countries on three continents: Peru, Thailand, South Africa, Kenya, Côte d'Ivoire, Botswana, Democratic Republic of the Congo, Nigeria, and Tanzania (Fig. 1; see also Table S1 in the supplemental material). The association between the fitness of isoniazid resistance-conferring mutations and HIV coinfection was tested in a univariate analysis (Fig. S1). Isoniazid resistance-conferring mutations were divided into three groups, as previously described (23): katG S315T mutation, katG mutations other than S315T, and inhA promoter mutations only. The S315T substitution in katG causes high-level isoniazid resistance while retaining some catalase/peroxidase functions (24). Conversely, the inhA promoter mutation does not affect KatG activity. Other substitutions/deletions in katG have been associated with a lower fitness in the laboratory and are observed only rarely among clinical isolates $(23,25,26)$. In the case of rifampicin, the association between the fitness of $r p o B$ variants and HIV coinfection was tested in both a univariate and multivariate analysis (Table 1). Resistanceconferring variants in $r p o B$ were classified into two groups based on their fitness effects documented previously $(11,20,27)$. The mutation rpoB S450L was considered high fitness, since this mutation was previously shown to confer a low fitness cost in the laboratory (11) and is generally the most common in clinical strains (28). Any other resistance-conferring variant affecting $r p o B$ was considered low fitness (11). The multivariable logistic regression model with outcome of low-fitness $r p o B$ variants was adjusted for host-related factors (history of TB, country of isolation, sex, and age) (29) and bacterial factors ( $M$. tuberculosis lineage, presence of an $r p o A-C$ compensatory mutation, clustering of the genome inferred by genetic relatedness). Seventy-six patients from Tanzania and Botswana were excluded from the model due to missing or unknown clinical data (see the supplemental methods file).

Out of 312 patients, 113 (36.2\%) were HIV coinfected, 120 (38.5\%) were women, 115 (36.9\%) were newly diagnosed TB cases (therefore, treatment naive), 276 (88.5\%) harbored isoniazid resistance-conferring mutations, with or without additional resistance, and 282 (90.4\%) harbored rifampicin resistance-conferring mutations, with or without additional resistance. In total, $78.8 \%(n=246)$ of the strains were classified as being at least multidrug resistant, defined as resistance to isoniazid and rifampicin with or without additional resistance to second-line drugs. Among the 113 HIV-coinfected 


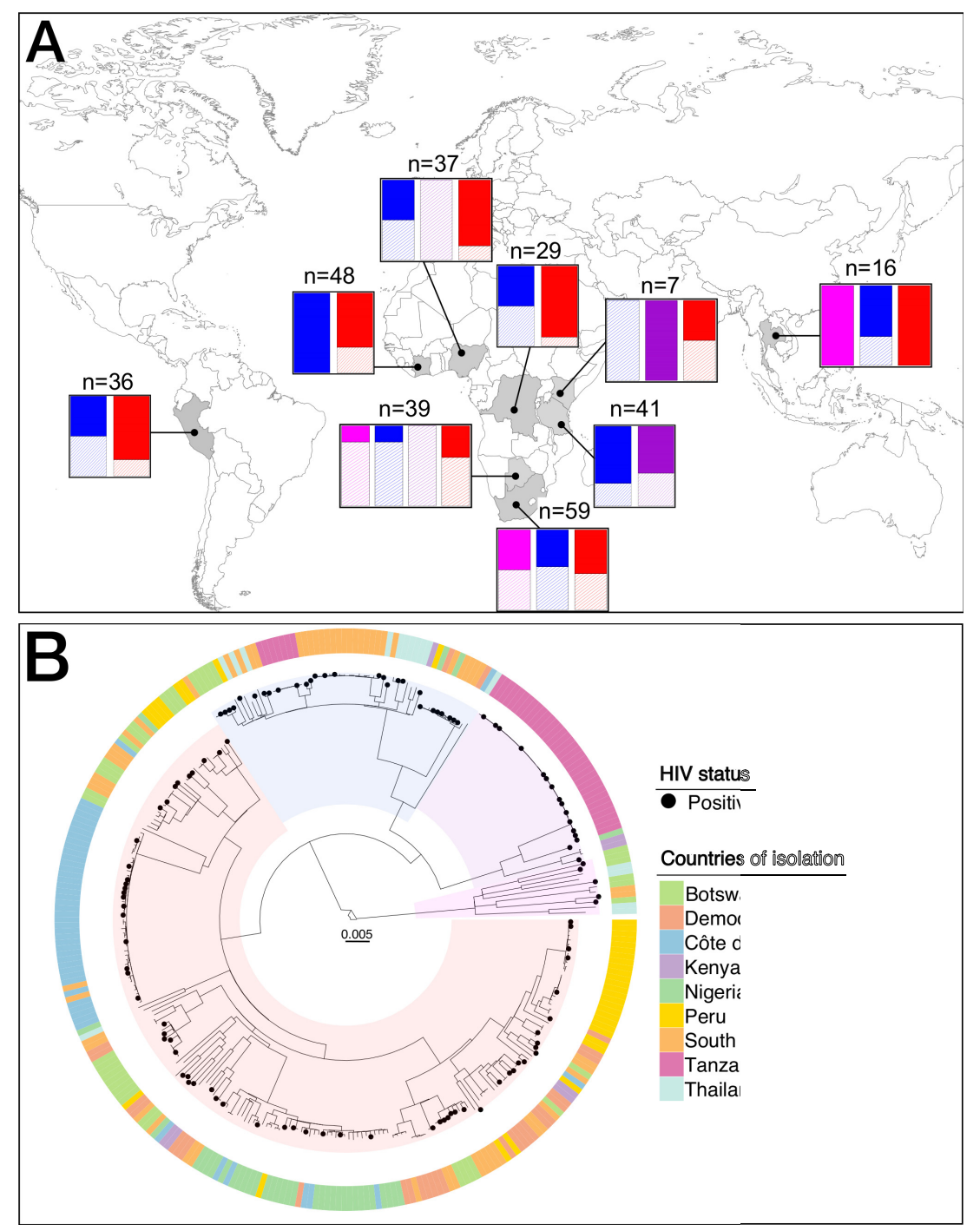

FIG 1 (A) Frequency of M. tuberculosis lineages by HIV status for countries sampled. Countries colored in gray were sampled. The bar plots indicate the proportion of each lineage represented in this study. Magenta corresponds to $M$. tuberculosis lineage 1, blue corresponds to $M$. tuberculosis lineage 2, purple corresponds to $M$. tuberculosis lineage 3, and red corresponds to M. tuberculosis lineage 4. Solid color corresponds to HIV-negative patients, and hatches correspond to HIV-coinfected TB patients. The number of genomes sampled in each country is indicated on top of the bar plots. (B) Phylogenetic tree of the data set used in the study. Maximum likelihood phylogeny of 312 whole-genome sequences based on 18,531 variable positions. The scale bar indicates the number of substitutions per polymorphic site. The phylogeny was rooted on Mycobacterium canettii. M. tuberculosis strains isolated from HIV-coinfected patients are indicated by black dots. The peripheral ring depicts the country of isolation of the strains sequenced.

individuals, 34 (30\%) were on antiretroviral therapy (ART), 26 (23\%) were not, and 53 (47\%) had an unknown ART start date. Four of the eight known M. tuberculosis lineages were represented in the following proportions: 11 L1 (3.5\%), 57 L2 (18.3\%), 38 L3 (12.2\%), and 206 L4 (66.0\%). After dividing a total of 276 isoniazid-resistant strains into the three groups of isoniazid resistance-conferring mutations defined above, we found similar proportions in HIV-coinfected and HIV-uninfected patients (chi-square test, $P=0.54$; Fig. S1), and, as expected, the katG S315T mutation was the most frequent mutation in both categories (overall, found in $80 \%$ of isoniazid-resistant strains). In the case of rifampicin resistance, a univariate and multivariate analysis of 203 strains with complete clinical records indicated that HIV-coinfected TB patients carried a higher proportion of low-fitness $r p o B$ resistance variants than HIV-negative patients $(72.3 \%$ 
TABLE 1 Results of the univariate and multivariate analysis showing host and bacterial factors associated with low fitness rpoB variants in 203 TB patients ${ }^{a}$

\begin{tabular}{|c|c|c|c|c|c|c|}
\hline \multirow[b]{2}{*}{ Parameter for fitness of $r p o B$ variants } & \multicolumn{2}{|c|}{$\begin{array}{l}\text { No. (\%) of patients by } \\
\text { fitness level }\end{array}$} & \multicolumn{2}{|l|}{ Univariable } & \multicolumn{2}{|l|}{ Multivariable } \\
\hline & Low & High & OR $(95 \% \mathrm{CI})$ & $P$ value & OR $(95 \% \mathrm{CI})$ & $P$ value \\
\hline \multicolumn{7}{|l|}{ HIV status } \\
\hline $\mathrm{HIV}^{-}$ & $71(51.4)$ & $67(48.6)$ & Reference & & Reference & \\
\hline $\mathrm{HIV}^{+}$ & $47(72.3)$ & $18(27.7)$ & $2.46(1.30-4.66)$ & 0.006 & $4.58(1.69-12.44)$ & 0.003 \\
\hline \multicolumn{7}{|c|}{ Presence of a compensatory mutation in $\operatorname{rpo} A-C$} \\
\hline No & $117(71.3)$ & $47(28.7)$ & Reference & & Reference & \\
\hline Yes & $1(2.6)$ & $38(97.4)$ & $0.01(0.00-0.08)$ & $<0.0001$ & $0.01(0.00-0.06)$ & $<0.0001$ \\
\hline \multicolumn{7}{|l|}{ M. tuberculosis lineage } \\
\hline 2 & $16(44.4)$ & $20(55.6)$ & Reference & & Reference & \\
\hline 4 & $99(61.5)$ & $62(38.5)$ & $2.00(0.96-4.14)$ & 0.06 & $3.10(0.94-10.21)$ & 0.06 \\
\hline Other (L1 or L3) & $3(50.0)$ & $3(50.0)$ & $1.25(0.22-7.05)$ & 0.80 & $0.97(0.11-8.31)$ & 0.98 \\
\hline \multicolumn{7}{|l|}{ Clustering of the genome } \\
\hline No & 109 (59.6) & $74(40.4)$ & Reference & & Reference & \\
\hline Yes & $9(45.0)$ & $11(55.0)$ & $0.56(0.22-1.41)$ & 0.21 & $1.05(0.28-3.90)$ & 0.94 \\
\hline \multicolumn{7}{|l|}{ Country of isolation } \\
\hline South Africa & $29(55.8)$ & $23(44.2)$ & Reference & & Reference & \\
\hline Democratic Republic of Congo & $11(37.9)$ & $18(62.1)$ & $0.48(0.19-1.23)$ & 0.13 & $0.39(0.12-1.34)$ & 0.14 \\
\hline Côte d'Ivoire & $35(79.5)$ & $9(20.5)$ & $3.08(1.24-7.70)$ & 0.02 & $2.04(0.58-7.23)$ & 0.27 \\
\hline Kenya & $4(66.7)$ & $2(33.3)$ & $1.59(0.27-9.44)$ & 0.61 & $0.94(0.10-8.42)$ & 0.96 \\
\hline Nigeria & $20(58.8)$ & $14(41.2)$ & $1.13(0.47-2.72)$ & 0.78 & $1.00(0.29-3.40)$ & 0.99 \\
\hline Peru & $16(53.3)$ & $14(46.7)$ & $0.91(0.37-2.23)$ & 0.83 & $1.49(0.33-6.70)$ & 0.60 \\
\hline Thailand & $3(37.5)$ & $5(62.5)$ & $0.48(0.10-2.20)$ & 0.34 & $0.42(0.07-2.65)$ & 0.36 \\
\hline \multicolumn{7}{|l|}{ Age } \\
\hline Mean (SD) & $32.5(10.4)$ & $34.3(12.3)$ & $0.99(0.96-1.01)$ & 0.25 & $0.97(0.94-1.01)$ & 0.10 \\
\hline \multicolumn{7}{|l|}{ Sex } \\
\hline Female & $47(59.5)$ & $32(40.5)$ & Reference & & & \\
\hline Male & $71(57.3)$ & $53(42.7)$ & $0.91(0.51-1.62)$ & 0.75 & $0.77(0.34-1.71)$ & 0.52 \\
\hline \multicolumn{7}{|l|}{ History of TB disease } \\
\hline No & $35(52.2)$ & $32(47.8)$ & Reference & & & \\
\hline Yes & $83(61.0)$ & $53(39.0)$ & $1.43(0.79-2.58)$ & 0.23 & $0.96(0.34-2.73)$ & 0.94 \\
\hline
\end{tabular}

${ }^{a}$ Number of observations in model, 203; $\mathrm{Cl}$, confidence interval. The odds ratios and $P$ values were obtained from the regression model.

versus $51.4 \%)$. The univariate analysis showed higher odds of having a low-fitness $r p o B$ variant in HIV-coinfected patients (odds ratio, 2.46 [95\% confidence interval, 1.30 to 4.66], $P=0.006$ ) (Table 1). Our multivariable regression analysis confirmed these results and showed an association between low-fitness $r p o B$ variants and HIV coinfection while controlling for other factors (odds ratio, 4.58 [95\% confidence interval, 1.69, 12.44], $P=0.003$ ) (Table 1). This association can be explained in at least two ways. First, HIV-coinfected patients are thought to have fewer lung cavities on average and lower sputum bacillary load $(30,31)$. The resulting smaller $M$. tuberculosis population size would lead to fewer replication events, possibly reducing the number of mutations available for selection to act upon. In other words, low-fitness variants and high-fitness variants would co-occur less often in an HIV-coinfected patient, such that competition between them would be less likely. This scenario would be relevant for de novo acquisition of low-fitness drug-resistant variants within an HIV-coinfected patient. Second, following the transmission of a drug-resistant strain with low fitness to a host with reduced immunity, weaker immune pressure acting on this strain might lead to better bacterial survival. The association between low-fitness rpoB variants and HIV coinfection remained significant even after adjusting for the different epidemiologic settings (i.e., countries) and the strain genetic background (i.e., M. tuberculosis lineages). We also observed that strains carrying the rpoB S450L resistance-conferring mutation 
were more likely to also carry a compensatory mutation in $r p o A-C$ (97.4\% versus $2.6 \%)$ (Table 1). Even though this phenomenon seems counterintuitive, it has been described multiple times $(7,9,32-34)$ and, thus, might point to different mechanisms of compensation in strains carrying resistance mutations other than $r p o B$ S450L. In addition, in our study, L4 strains were associated with low-fitness rpoB variants compared to L2 (odds ratio, 3.10 [95\% confidence interval, 0.94, 10.21], $P=0.06$ ) (Table 1), indicating that the strain genetic background plays a role in shaping the cost of resistance, as was previously shown for other bacterial species (35) and for other drugs (36). In the regression analysis, we had several categorical variables with only a few observations. Therefore, statistical power, especially for country of isolation, was low, and the results should be interpreted with care.

HIV-coinfected TB patients are generally thought to have a reduced potential for TB transmission $(30,37)$, because these patients have reduced formation of lung cavities, more extrapulmonary disease, and a shorter period of infectiousness due to earlier diagnosis or higher mortality, especially in the absence of antiretroviral treatment and if antibiotic resistance is already present (4). Based on the overrepresentation of low-fitness $r p o B$ mutations in the context of HIV coinfection, one would expect a further reduction of the transmission potential of drug-resistant TB in this context. However, outbreaks of drug-resistant TB in HIV-coinfected patients have been reported (3). Such outbreaks might be explained by (i) a higher risk of $M$. tuberculosis infection and reinfection due to diminished host immunity, (ii) on-going transmission of drugresistant $M$. tuberculosis from a larger pool of immunocompetent TB patients to immunocompromised patients, (iii) transmission occurring in conducive environments, such as health care settings, where both HIV-coinfected individuals and drug-resistant TB patients are more likely to coexist, and (iv) M. tuberculosis strains carrying highfitness drug resistance mutations.

In summary, using a global sample of drug-resistant $M$. tuberculosis clinical strains from HIV-coinfected and HIV-negative TB patients, we showed that low-fitness rpoB variants were overrepresented in HIV-coinfected patients, and that this association was independent from other potential confounding factors. Taken together, our results provide new insights into how HIV coinfection can impact the fitness of drug-resistant M. tuberculosis.

Data availability. The $M$. tuberculosis whole-genome sequences from the patients are available on NCBI under several project identifiers. The accession number for each genome is indicated in Supplemental Table S1.

\section{SUPPLEMENTAL MATERIAL}

Supplemental material is available online only.

SUPPLEMENTAL FILE 1, PDF file, 0.1 MB.

SUPPLEMENTAL FILE 2, XLSX file, $0.03 \mathrm{MB}$.

\section{ACKNOWLEDGMENTS}

We thank all the sites that participated in this study and the patients whose data were used in this study. We thank Jan Hattendorf for providing statistical help and Sebastian M. Gygli for critically reading the manuscript. Calculations were performed at the sciCORE (http://scicore.unibas.ch/) scientific computing core facility at University of Basel.

This research was supported by the Swiss National Science Foundation (grant numbers 153442, 310030_188888, 174281, and IZRJZ3_164171). The International Epidemiology Databases to Evaluate AIDS (leDEA) is supported by the U.S. National Institutes of Health's National Institute of Allergy and Infectious Diseases, the Eunice Kennedy Shriver National Institute of Child Health and Human Development, the National Cancer Institute, the National Institute of Mental Health, the National Institute on Drug Abuse, the National Heart, Lung, and Blood Institute, the National Institute on Alcohol Abuse and Alcoholism, the National Institute of Diabetes and Digestive and Kidney Diseases, the Fogarty International Center, and the National Library of Medicine: 
Asia-Pacific, U01AI069907; CCASAnet, U01Al069923; Central Africa, U01AI096299; East Africa, U01Al069911; NA-ACCORD, U01AI069918; Southern Africa, U01AI069924; and West Africa, U01A1069919. Informatics resources are supported by the Harmonist Project, R24AI124872. This work is solely the responsibility of the authors and does not necessarily represent the official views of any of the institutions mentioned above. R.J.W. is supported by the Francis Crick Institute, which receives funding from Wellcome (FC0010218), CRUK (FC0010218), and UKR1 (FC0010218). He is also supported by Wellcome (104803 and 203135).

\section{REFERENCES}

1. World Health Organization. 2019. Global tuberculosis report 2019. World Health Organization, Geneva, Switzerland. https:/apps.who.int/iris/ bitstream/handle/10665/329368/9789241565714-eng.pdf?ua=1.

2. Getahun H, Gunneberg C, Granich R, Nunn P. 2010. HIV infection-associated tuberculosis: the epidemiology and the response. Clin Infect Dis 50:S201-S207. https://doi.org/10.1086/651492.

3. Wells CD, Cegielski JP, Nelson LJ, Laserson KF, Holtz TH, Finlay A, Castro KG, Weyer K. 2007. HIV infection and multidrug-resistant tuberculosis-the perfect storm. J Infect Dis 196:S86-S107. https://doi .org/10.1086/518665.

4. Gandhi NR, Moll A, Sturm AW, Pawinski R, Govender T, Lalloo U, Zeller K, Andrews J, Friedland G. 2006. Extensively drug-resistant tuberculosis as a cause of death in patients co-infected with tuberculosis and HIV in a rural area of South Africa. Lancet 368:1575-1580. https://doi.org/10 .1016/S0140-6736(06)69573-1.

5. Eldholm V, Rieux A, Monteserin J, Lopez JM, Palmero D, Lopez B, Ritacco V, Didelot X, Balloux F. 2016. Impact of HIV co-infection on the evolution and transmission of multidrug-resistant tuberculosis. Elife 5:1-19. https://doi.org/10.7554/eLife.16644.

6. Cohen T, Murray M. 2004. Modeling epidemics of multidrug-resistant M. tuberculosis of heterogeneous fitness. Nat Med 10:1117-1121. https:// doi.org/10.1038/nm1110.

7. Comas I, Borrell S, Roetzer A, Rose G, Malla B, Kato-Maeda M, Galagan J, Niemann S, Gagneux S. 2011. Whole-genome sequencing of rifampicinresistant Mycobacterium tuberculosis strains identifies compensatory mutations in RNA polymerase genes. Nat Genet 44:106-110. https://doi .org/10.1038/ng.1038.

8. Casali N, Nikolayevskyy V, Balabanova Y, Ignatyeva O, Kontsevaya I, Harris SR, Bentley SD, Parkhill J, Nejentsev S, Hoffner SE, Horstmann RD, Brown T, Drobniewski F. 2012. Microevolution of extensively drugresistant tuberculosis in Russia. Genome Res 22:735-745. https://doi.org/ 10.1101/gr.128678.111

9. De Vos M, Müller B, Borrell S, Black PA, Van Helden PD, Warren RM, Gagneux S, Victor TC. 2013. Putative compensatory mutations in the rpoc gene of rifampin-resistant mycobacterium tuberculosis are associated with ongoing transmission. Antimicrob Agents Chemother 57: 827-832. https://doi.org/10.1128/AAC.01541-12.

10. Shcherbakov D, Akbergenov R, Matt T, Sander P, Andersson DI, Böttger EC. 2010. Directed mutagenesis of mycobacterium smegmatis 16S rRNA to reconstruct the in vivo evolution of aminoglycoside resistance in mycobacterium tuberculosis. Mol Microbiol 77:830-840. https://doi.org/ 10.1111/j.1365-2958.2010.07218.x.

11. Gagneux S, Long CD, Small PM, Van T, Schoolnik GK, Bohannan BJM. 2006. The competitive cost of antibiotic resistance in Mycobacterium tuberculosis. Science 312:1944-1946. https://doi.org/10.1126/science .1124410 .

12. Sander P, Springer B, Prammananan T, Sturmfels A, Kappler M, Pletschette $M$, Böttger EC. 2002. Fitness cost of chromosomal drug resistance-conferring mutations. Antimicrob Agents Chemother 46: 1204-1211. https://doi.org/10.1128/aac.46.5.1204-1211.2002.

13. Dye C, Williams BG, Espinal MA, Raviglione MC. 2002. Erasing the world's slow stain: strategies to beat multidrug-resistant tuberculosis. Science 295:2042-2046. https://doi.org/10.1126/science.1063814.

14. Cohen T, Dye C, Colijn C, Williams B, Murray M. 2009. Mathematical models of the epidemiology and control of drug-resistant TB. Expert Rev Respir Med 3:67-79. https://doi.org/10.1586/17476348.3.1.67.

15. Borrell S, Gagneux S. 2009. Infectiousness, reproductive fitness and evolution of drug-resistant Mycobacterium tuberculosis. Int J Tuber Lung Dis 13:1456-1466.
16. Mesfin YM, Hailemariam D, Biadglign S, Kibret KT. 2014. Association between HIV/AIDS and multi-drug resistance tuberculosis: a systematic review and meta-analysis. PLoS One 9:e82235. https://doi.org/10.1371/ journal.pone.0082235.

17. Suchindran S, Brouwer ES, Van Rie A. 2009. Is HIV infection a risk factor for multi-drug resistant tuberculosis? A systematic review. PLoS One 4:e5561. https://doi.org/10.1371/journal.pone.0005561.

18. Khan PY, Yates TA, Osman M, Warren RM, van der Heijden $Y$, Padayatchi N, Nardell EA, Moore D, Mathema B, Gandhi N, Eldholm V, Dheda K, Hesseling AC, Mizrahi V, Rustomjee R, Pym A. 2019. Transmission of drug-resistant tuberculosis in HIV-endemic settings. Lancet Infect Dis 19:e77-e88. https://doi.org/10.1016/S1473-3099(18)30537-1.

19. Ssengooba W, Lukoye D, Meehan CJ, Kateete DP, Joloba ML, De Jong BC, Cobelens FG, Van Leth F. 2017. Tuberculosis resistance-conferring mutations with fitness cost among HIV-positive individuals in Uganda. Int J Tuber Lung Dis 21:531-536. https://doi.org/10.5588/ijtld.16.0544.

20. Billington OJ, Mchugh TD, Gillespie SH. 1999. Physiological cost of rifampin resistance induced in vitro in Mycobacterium tuberculosis. Antimicrob Agents Chemother 43:1866-1869. https://doi.org/10.1128/ AAC.43.8.1866.

21. Egger M, Ekouevi DK, Williams C, Lyamuya RE, Mukumbi $H$, Braitstein $P$, Hartwell T, Graber C, Chi BH, Boulle A, Dabis F, Wools-Kaloustian K. 2012. Cohort profile: the international epidemiological databases to evaluate AIDS (leDEA) in sub-Saharan Africa. Int J Epidemiol 41:1256-1264. https://doi.org/10.1093/ije/dyr080.

22. Mcgowan CC, Cahn P, Gotuzzo E, Padgett D, Pape JW, Wolff M Schechter M, Masys DR. 2007. Cohort profile: Caribbean, Central and South America Network for HIV research (CCASAnet) collaboration within the International Epidemiologic Databases to Evaluate AIDS (leDEA) programme. Int J Epidemiol 36:969-976. https://doi.org/10 $.1093 /$ ije/dym073.

23. Gagneux S, Burgos MV, DeRiemer K, Enciso A, Muñoz S, Hopewell PC, Small PM, Pym AS. 2006. Impact of bacterial genetics on the transmission of isoniazid-resistant Mycobacterium tuberculosis. PLoS Pathog 2:e61. https://doi.org/10.1371/journal.ppat.0020061.

24. Pym AS, Saint-Joanis B, Cole ST. 2002. Effect of katG mutations on the virulence of Mycobacterium tuberculosis and the implication for transmission in humans. Infect Immun 70:4955-4960. https://doi.org/10 .1128/iai.70.9.4955-4960.2002.

25. Heym B, Alzari PM, Honore N, Cole ST. 1995. Missense mutations in the catalsase-peroxidase gene, katG, are associated with isoniazid resistance in Mycobacterium tuberculosis. Mol Microbiol 15:235-245. https://doi .org/10.1111/j.1365-2958.1995.tb02238.x

26. van Soolingen D, de Haas PEW, van Doorn HR, Kuijper E, Rinder $H$, Borgdorff MW. 2000. Mutations at amino acid position 315 of the katG gene are associated with high-level resistance to isoniazid, other drug resistance, and successful transmission of Mycobacterium tuberculosis in The Netherlands. J Infect Dis 182:1788-1790. https://doi.org/10.1086/ 317598.

27. Mariam DH, Mengistu Y, Hoffner SE, Andersson DI. 2004. Effect of rpoB mutations conferring rifampin resistance on fitness of Mycobacterium tuberculosis. Antimicrob Agents Chemother 48:1289-1294. https://doi .org/10.1128/aac.48.4.1289-1294.2004.

28. Sandgren A, Strong M, Muthukrishnan P, Weiner BK, Church GM, Murray MB. 2009. Tuberculosis drug resistance mutation database. PLoS Med 6:e1000002. https://doi.org/10.1371/journal.pmed.1000002.

29. Zürcher K, Ballif M, Fenner L, Borrell S, Keller PM, Gnokoro J, Marcy O, Yotebieng M, Diero L, Carter EJ, Rockwood N, Wilkinson RJ, Cox H, Ezati $\mathrm{N}$, Abimiku AG, Collantes J, Avihingsanon A, Kawkitinarong K, Reinhard 
M, Hömke R, Huebner R, Gagneux S, Böttger EC, Egger M, Zürcher $K$ Egger M, Fenner L, Ballif M, Chammartin F, Gagneux S, Borrell S, Reinhard M, Boettger EC, Keller P, Hömke R, Abimiku A, Ezati N, Yotebieng M, Wenzi L, Tabala M, Cox H, Rockwood N, Warren R, Streicher E, Wilkinson RJ, Carter EJ, Diero L, Collantes J, Zamudio C, Huebner R, Sohn A, Avihingsanon A, Petersen T, Kawkitinarong K, Kasipong N, Gnokoro J, N'Guessan K, Marcy O. 2019. Drug susceptibility testing and mortality in patients treated for tuberculosis in high-burden countries: a multicentre cohort study. Lancet Infect Dis 19:298-307. https://doi.org/10.1016/ S1473-3099(18)30673-X.

30. Kwan C, Ernst JD. 2011. HIV and tuberculosis: a deadly human syndemic. Clin Microbiol Rev 24:351-376. https://doi.org/10.1128/CMR.00042-10.

31. Hanrahan CF, Theron G, Bassett J, Dheda K, Scott L, Stevens W, Sanne I, Van Rie A. 2014. Xpert MTB/RIF as a measure of sputum bacillary burden: variation by HIV status and immunosuppression. Am J Respir Crit Care Med 189:1426-1434. https://doi.org/10.1164/rccm.201312-21400C.

32. Casali N, Nikolayevskyy V, Balabanova Y, Harris SR, Ignatyeva O, Kontsevaya I, Corander J, Bryant J, Parkhill J, Nejentsev S, Horstmann RD, Brown T, Drobniewski F. 2014. Evolution and transmission of drugresistant tuberculosis in a Russian population. Nat Genet 46:279-286. https://doi.org/10.1038/ng.2878.

33. Eldholm V, Monteserin J, Rieux A, Lopez B, Sobkowiak B, Ritacco V, Balloux F. 2015. Four decades of transmission of a multidrug-resistant
Mycobacterium tuberculosis outbreak strain. Nat Commun 6:7119. https://doi.org/10.1038/ncomms8119.

34. Song T, Park Y, Shamputa IC, Seo S, Lee SY, Jeon HS, Choi H, Lee M, Glynne RJ, Barnes SW, Walker JR, Batalov S, Yusim K, Feng S, Tung CS, Theiler J, Via LE, Boshoff HIM, Murakami KS, Korber B, Barry CE, Cho SN. 2014. Fitness costs of rifampicin resistance in Mycobacterium tuberculosis are amplified under conditions of nutrient starvation and compensated by mutation in the $\beta^{\prime}$ subunit of RNA polymerase. Mol Microbiol 91:1106-1119. https://doi.org/10.1111/mmi.12520.

35. Vogwill T, Kojadinovic M, MacLean RC. 2016. Epistasis between antibiotic resistance mutations and genetic background shape the fitness effect of resistance across species of Pseudomonas. Proc Biol Sci 283:20160151. https://doi.org/10.1098/rspb.2016.0151.

36. Castro RAD, Ross A, Kamwela L, Reinhard M, Loiseau C, Feldmann J, Borrell S, Trauner A, Gagneux S. 2020. The genetic background modulates the evolution of fluoroquinolone-resistance in Mycobacterium tuberculosis. Mol Biol Evol 37:195-207. https://doi.org/10.1093/molbev/ msz214.

37. Huang CC, Tchetgen ET, Becerra MC, Cohen T, Hughes KC, Zhang Z, Calderon R, Yataco R, Contreras C, Galea J, Lecca L, Murray M. 2014. The effect of HIV-related immunosuppression on the risk of tuberculosis transmission to household contacts. Clin Infect Dis 58:765-774. https:// doi.org/10.1093/cid/cit948. 